\title{
Comparative analysis of local infiltration of tonsillar fossa with bupivacaine versus dexamethasone on post tonsillectomy morbidity
}

\author{
Aruna K. ${ }^{1}$, Sukthankar P.S. ${ }^{2}$, Raga P.S. ${ }^{3}$ \\ ${ }^{1}$ Dr. Kommineni Aruna, ${ }^{2}$ Dr. P.S. Sukthankar, ${ }^{3}$ Dr. Preeti S. Raga, all authors are affiliated with Department of ENT, \\ Kamineni Institute of Medical Sciences, Narketpally, Nalgonda District, Telangana State, India. \\ Corresponding Author: Dr. Kommineni Aruna, Assistant Professor, Department of ENT, Kamineni Institute of Medical \\ Sciences, Narketpally, Nalgonda District, Telangana State, India. E-mail: kommineniaruna@gmail.com
}

\begin{abstract}
Background: Tonsillectomy is one of the most common surgery performed in pediatric otorhinolaryngology. Pain and vomiting being the usual morbidity following this surgery. Aim \& Objective: To compare the efficacy of infiltration of Bupivacaine versus dexamethasone into the tonsillar fossa in postoperative pain and vomiting. Methods: A total of 100 patients, aged 10-30 years of both sexes with chronic tonsillitis accrued into the study. They were divided in to two groups A and B. Group A was infiltrated with $0.5 \%$ bupivacaine ( $1 \mathrm{mg} / \mathrm{kg}$ body weight) locally and Group B with dexamethasone $(0.15 \mathrm{mg} / \mathrm{kg}$ bodyweight $)$ locally into the tonsillar bed. All patients underwent tonsillectomy by dissection/snare technique, bleeding was controlled by applying local pressure, and by ligatures, thereby avoiding cauterization. Post tonsillectomy pain assessed by visual analog scale (VAS), nausea and vomiting by absence/presence was compared between both groups. Results: In Bupivacaine group (A), 86\% patients observed analgesic effect by the $1^{\text {st }}$ postoperative hour and by $6^{\text {th }}$ hour all had complete analgesia. In dexamethasone group (B) the analgesic effect started by $12^{\text {th }}$ hour and by $48^{\text {th }}$ hour in all patients $(\mathrm{p}<0.001)$. Post-operative occurrence of nausea and vomiting in bupivacaine group (A) was $76 \%$ and 30\% respectively. However, in dexamethasone group (B), the nausea and vomiting was observed in $10 \%$ respectively. Conclusion: Our study showed that $0.5 \%$ bupivacaine reduces immediate post-operative pain significantly as compared to dexamethasone and dexamethasone reduces postoperative nausea and vomiting significantly as compared to $0.5 \%$ bupivacaine. There were no adverse reactions or complications due to the additional surgical intervention in both the groups.
\end{abstract}

Keywords: Dexamethasone, Bupivacaine, pain, vomiting, Tonsillectomy.

\section{Introduction}

Tonsillectomy is still one of the most common operations being done in otorhinolaryngology [1,2]. Severe pain following tonsillectomy has a negative impact on the patient's well-being due to impaired swallowing, and this increases the risk of secondary infection, bleeding and dehydration [3]. Different methods have been followed to reduce the pain including intra operative and post-operative anaesthetic pain regimens, like parenteral diclofenac sodium, adjustment of surgical techniques, local infiltration of local anesthetic agents and parenteral steroids with varying results.

There are surgical modalities such as laser, cryotherapy, and recently coblation which are used for reducing pain

Manuscript received: $16^{\text {th }}$ August 2019

Reviewed: $25^{\text {th }}$ August 2019

Author Corrected: $30^{\text {th }}$ August 2019

Accepted for Publication: $3^{\text {rd }}$ September 2019 and bleeding, However, pain persists in all the modalities with varying degrees [4]. A study by Mallanagoudar Hallaswami [5] compared the effects of pre-operative intravenous dexamethasone with local infiltration of bupivacaine. Among these two groups, bupivacaine showed significant reduction in post tonsillectomy pain and early oral intake of liquid and solid diet whereas dexamethasone infusion significantly reduced postoperative nausea and vomiting [5].

Another study by Gao W, Zhang QR, Jiang et al; Compared effect of local and Intravenous dexamethasone for postoperative pain and recovery after tonsillectomy. In his study Local infiltration of dexamethasone was more effective than systemic administration to decrease pain and time to food intake, but the antiemetic effect was less [6]. In the above studies it is seen that local infiltration of bupivacaine is 


\section{Original Research Article}

superior to intravenous dexamethasone and infiltration of dexamethasone is also superior to intravenous dexamethasone. Literature review did not reveal any study comparing local infiltration of Dexamethasone $(0.15 \mathrm{mg} / \mathrm{kg})$ with bupivacaine infiltration $(1 \mathrm{mg} / \mathrm{kg})$ on post tonsillectomy morbidities of pain, nausea, vomiting, and odynophagia. Hence this study was aimed to compare the effects of local infiltration of tonsillar fossa with Bupivacaine versus dexamethasone on post tonsillectomy pain and vomiting

\section{Materials and Methods}

This present clinical study was conducted at Department of Otorhinolaryngology, Rural tertiary care medical college and hospital in Nalgonda District, Telangana state, during the period October 2015 to September 2017. After getting approval from the institutional ethical committee and after obtaining patient's valid informed consent, this prospective study was conducted on 100 cases of chronic tonsillitis diagnosed clinically from patients attending the department of ENT.

\section{Inclusion criteria}

1. All patients posted for tonsillectomy and willing for the study.

2. All patients aged above 10 years.

\section{Exclusion criteria}

1. Past history of Peritonsillitis / Peritonsillar abscess.

2. History of Acid peptic disorders.

3. Patients Hypersensitive to Bupivacaine.

4. Patients hypersensitive to Dexamethasone.

5. Cushing's disease.

6. Diabetes Mellitus.
100 patients were divided into two groups $\mathrm{A}$ and $\mathrm{B}$ by randomization.

1. Group A (50 cases)- Given $0.5 \%$ bupivacaine $(1 \mathrm{mg} / \mathrm{kg})$ locally into the tonsillar bed.

2. Group B (50 cases)- Given dexamethasone $(0.15 \mathrm{mg} / \mathrm{kg})$ locally into the tonsillar bed.

Aneasthesia: General anesthesia with Oro/nasal Endotracheal Intubation.

Technique: Dissection and snare method.

After the tonsillectomy procedure and hemostasis, each tonsillar fossa was infiltrated either with bupivacaine or dexamethasone depending up on the group at three places i.e., at upper pole, tonsillar bed \& lower pole. Dosages of the drugs were calculated for the weight of the given case. $0.5 \%$ Bupivacaine $(1 \mathrm{mg} / \mathrm{kg} / \mathrm{body}$ weight) was injected for group A patients and Dexamethasone $(0.15 \mathrm{mg} / \mathrm{kg} /$ body weight $)$ was injected for group B patients. As per visual analog scale, pain score was recorded at 1, 3, 6, 12, 24, 48 hours. Recording of presence or absence of nausea and vomiting was done. All the data was entered in to individual proforma accordingly. All these were done by doctors who were blind to the group of the patient.

Statistical analysis: The analysis was performed using SPSS software version 19. The values were expressed as mean and standard deviation. Categorical data were given as numbers and percentages. Wilcoxon Signed Ranks test has been used to find the significance of pain score between both the groups. CHISQUARE test was also used to determine significant differences between both groups. The p-values less than 0.05 were considered statistically significant.

\section{Results}

In our study, 100 patients were divided into two groups by randomization and distributed the local infiltrative agents among groups.

1. Group A $-0.5 \%$ bupivacaine $(1 \mathrm{mg} / \mathrm{kg})$ infiltrated locally into the tonsillar bed.

2. Group B- Dexamethasone $(0.15 \mathrm{mg} / \mathrm{kg})$ infiltrated locally into the tonsillar bed.

Analysis of age wise distribution revealed that $76 \%$ of patients of group A and $80 \%$ of patients of group B were in $2^{\text {nd }}$ decade. $3^{\text {rd }}$ decade had $16 \%$ of patients in both the groups (Table 1 ).

Table No-1: Age distribution of patients.

\begin{tabular}{|c|c|c|}
\hline Age (Years) & Group A & Group B \\
\hline $10-20$ & $38(76 \%)$ & $40(80 \%)$ \\
\hline $21-30$ & $8(16 \%)$ & $8(16 \%)$ \\
\hline$>31$ & $4(8 \%)$ & $2(4 \%)$ \\
\hline Total (n=100) & $\mathbf{5 0}$ & $\mathbf{5 0}$ \\
\hline
\end{tabular}


By 1st hour pain was absent in $62 \%$ of group A and $0 \%$ in group B. At the end of 12 hours $96 \%$ of patients were pain free in group A and 18\% in group B. At the end of 24 hours, pain was absent in $98 \%$ of group A and $76 \%$ of group B. P value was being statistically significant, which showed that bupivacaine had better analgesic effect as compared to dexamethasone in the first 24 hours. By $48^{\text {th }}$ hour there was no significant difference in reduction of pain in both the groups, $\mathrm{p}$ value being more than 0.05 (Table 2)

Table-2: Post-operative pain assessment by visual analog scale and comparison

\begin{tabular}{|c|c|c|c|c|}
\hline Post OP Hours & Pain & Group A $(N=50)$ & Group B $(N=50)$ & $\begin{array}{l}\text { P Value by CHI } \\
\text { square test }\end{array}$ \\
\hline \multirow{2}{*}{$1^{\text {st }}$} & Present & $19(38 \%)$ & $50(100 \%)$ & \multirow{2}{*}{$0.0001 *$} \\
\hline & Absent & $31(62 \%)$ & $0(0 \%)$ & \\
\hline \multirow{2}{*}{$3^{\text {rd }}$} & Present & $18(36 \%)$ & $50(100 \%)$ & \multirow{2}{*}{$0.0001 *$} \\
\hline & Absent & $32(64 \%)$ & $0(0 \%)$ & \\
\hline \multirow{2}{*}{$6^{\text {th }}$} & Present & $7(14 \%)$ & $50(100 \%)$ & \multirow{2}{*}{$0.0001 *$} \\
\hline & Absent & $43(86 \%)$ & $0(0 \%)$ & \\
\hline \multirow{2}{*}{12 th } & Present & $2(4 \%)$ & $41(18 \%)$ & \multirow{2}{*}{$0.0001 *$} \\
\hline & Absent & $48(96 \%)$ & $9(18 \%)$ & \\
\hline \multirow{2}{*}{24 th } & Present & $1(2 \%)$ & $12(24 \%)$ & \multirow{2}{*}{$0.001^{*}$} \\
\hline & Absent & $49(98 \%)$ & $38(76 \%)$ & \\
\hline \multirow{2}{*}{ 48th } & Present & $0(0 \%)$ & $2(4 \%)$ & \multirow{2}{*}{0.153} \\
\hline & Absent & $50(100 \%)$ & $48(96 \%)$ & \\
\hline
\end{tabular}

*Statistically significant

From $1^{\text {st }}$ hour up to the end of 24th hour the pain score of both the groups and the $\mathrm{P}$ value being statistically highly significant by Wilcoxon Signed Ranks test, which showed that bupivacaine had better analgesic effect as compared to dexamethasone in the first 24 hours. By $48^{\text {th }}$ hour there was no significant difference in reduction of pain in both the groups, p value being more than 0.05 (Table 3).

Table 3-Comparison of pain score among Group A \& B by Wilcoxon Signed Ranks test

\begin{tabular}{|c|c|}
\hline Postoperative Hours for Groups (A \& B) & P-value by Wilcoxon signed ranks test \\
\hline $1^{\text {st }}$ & $0.0000^{*}$ \\
\hline $3^{\text {rd }}$ & $0.0000^{*}$ \\
\hline $6^{\text {th }}$ & $0.0000^{*}$ \\
\hline $12^{\text {th }}$ & $0.0000^{*}$ \\
\hline $24^{\text {th }}$ & $0.001^{*}$ \\
\hline $48^{\text {th }}$ & 0.157 \\
\hline
\end{tabular}

* Statistically significant

Post-operative occurrence of nausea in bupivacaine infiltration group was $76 \%$ and $10 \%$ in dexamethasone infiltration group. $\mathrm{P}$ value $<0.001$ by Chi square test. There is clinically and statistically highly significant difference in both the groups (Table 4).

Table-4: Post-operative assessment of nausea.

\begin{tabular}{|c|c|c|c|}
\hline Nausea & $\begin{array}{c}\text { Group A } \\
\mathbf{( 0 . 5 \%} \text { Bupivacaine) } \\
(\mathbf{N = 5 0 )}\end{array}$ & $\begin{array}{c}\text { Group B } \\
\text { (Dexamethasone) (N=50) }\end{array}$ & $\begin{array}{c}\text { P value by CHI Square } \\
\text { test }\end{array}$ \\
\hline Present & $38(76 \%)$ & $05(10 \%)$ & $<0.001^{*}$ \\
\hline Absent & $12(24 \%)$ & $45(90 \%)$ & $<0.001^{*}$ \\
\hline
\end{tabular}

*Statistically significant 
Post-operative vomiting was seen in $10 \%$ subjects of dexamethasone infiltration group and $30 \%$ of bupivacaine infiltration group. There was statistically significant difference observed in both the groups $(\mathrm{P}<0.001)($ Table 5).

Table No V: Post-operative assessment of vomiting

\begin{tabular}{|c|c|c|c|}
\hline Vomiting & $\begin{array}{c}\text { Group A } \\
(\mathbf{0 . 5} \% \text { Bupivacaine) }\end{array}$ & $\begin{array}{c}\text { Group B } \\
\text { (Dexamethasone) }\end{array}$ & $\begin{array}{c}\text { P value by CHI } \\
\text { SQUARE test }\end{array}$ \\
\hline Present & $15(30 \%)$ & $05(10 \%)$ & $<0.001 *$ \\
\hline Absent & $35(70 \%)$ & $45(90 \%)$ & $<0.001 *$ \\
\hline
\end{tabular}

*Statistically significant

There were no complications in any of the groups either to the local infiltration, hemorrhage or increase in slough formation.

\section{Discussion}

Tonsillectomy is being done since antiquity and still continues to be one of the basic surgeries in otorhinolaryngology.

In spite of advancements in surgical and anaesthetic techniques; there is not much improvement in the postoperative pain, nausea and vomiting [7].

Oropharyngeal pain and irritation of gastric mucosa by swallowed blood are two main contributors towards high incidence of Postoperative Nausea and Vomiting following tonsillectomy [8].

Our study included patients of age group 10 years and above. Maximum numbers of patients were seen in $2^{\text {nd }}$ decade followed by $3^{\text {rd }}$ decade in both the groups.

The mean age was 16.9 years. One reason for this may be that they are growing, active and are exposed to various people with infections, though no age group is immune from tonsillitis.

More number of female patients was seen than male patients in both the groups (56\% and 60\%). In our study, there was significant reduction of pain in bupivacaine infiltration group of 50 patients and the same was found by the other authors also.

Hallaswami Mallanagoudar [5] found significant reduction of pain post operatively in bupivacaine group of 30 patients.

1

Even Kermat Mozafowinia and Marym Amizadeh [9] showed similar results in reduction of post-operative pain in bupivacaine infiltration group. Moreover, Bhadoria P et al (2006) [10] also found that bupivacaine group had significant reduction in post-operative pain.
Wei Gao, Zhang QR, Jiang et al [6] study found that local infiltration of dexamethasone showed significant reduction in post-operative pain in a group of 80 patients as compared to intravenous infusion of dexamethasone. Literature review did not reveal any other study comparing dexamethasone infiltration with either dexamethasone infusion or bupivacaine infiltration.

In our study, all the 50 patients of dexamethasone group had significant reduction of pain as compared to our historical patients in whom the pain starts abating after three days, whereas dexamethasone infiltration patients did not have pain after 48 hours.

However present study shows that pain reduction in bupivacaine infiltration group is superior to the dexamethasone infiltration group.

In Bupivacaine group; the analgesic effect started by the $1^{\text {st }}$ postoperative hour and by $6^{\text {th }}$ hour our $86 \%$ of subjects had no pain whereas in dexamethasone group the analgesic effect started around $12^{\text {th }}$ hour. However, by $48^{\text {th }}$ hour there was no significant difference in reduction of pain in both the groups.

In our study at 6th postoperative hour bupivacaine group had pain score $0-1$, whereas in dexamethasone group pain score was 4-5 and at 24 hours both groups had nearly same pain score of $0-1$. At 48 hours both the groups had pain score of 0 and thereafter there was no significant difference in pain for both bupivacaine and dexamethasone groups.

In other studies, authors mentioned that pain was less but they did not quantify the pain score, and hence the pain scores could not be compared with those studies. 


\section{Original Research Article}

A study by Mallanagoudar Hallaswami [5]: in his study $0.5 \%$ bupivacaine group showed significant increase in post-operative nausea and vomiting (PONV) as compared to dexamethasone infusion group.

In our study also $0.5 \%$ bupivacaine group showed statistically significant more post-operative nausea and vomiting as compared to dexamethasone infiltration group.

Wei Gao, Zhang QR, Jiang et all (2015) [6] in their study they found that local infiltration of dexamethasone group had more post-operative nausea and vomiting as compared to the dexamethasone infusion group.

In our study local infiltration of dexamethasone showed significant reduction in postoperative nausea and vomiting in a group of 50 patients compared to bupivacaine infiltration group. Among both the groups, nausea and vomiting incidence was analyzed separately.

Dexamethasone infiltration group showed a significant reduction in post-operative nausea i.e. incidence of nausea in bupivacaine group was $76 \%$ whereas it was $10 \%$ in dexamethasone group. Vomiting was present in $10 \%$ subjects of dexamethasone infiltration group and was significantly less than $30 \%$ of bupivacaine infiltration group.

Though dexamethasone was locally infiltrated, eventually gets absorbed into the body and must have been the cause for the reduction in postoperative nausea and vomiting.

The time to first administration of analgesic and average consumption of analgesic were less in bupivacaine group compared to dexamethasone group. These two aspects were not mentioned in other studies, hence could not be compared.

Local infiltration of either bupivacaine or dexamethasone into the tonsillar fossa did not cause any adverse effect postoperatively in that there was no increase in slough formation or any delay in healing.

There were no complications such as cervical abscess or airway obstruction after local infiltration of drugs [11, 12]. No adverse reactions to these medicines were seen in both the groups.

In the light of an increasing number of pediatric and adult tonsillectomies being performed as daycare cases, further studies are indicated to establish whether
Bupivacaine and Dexamethasone local infiltration as a standard method of providing post-operative analgesia, nausea and vomiting.

Limitations: The surgical technique is limited to dissection and snare method of tonsillectomy.

\section{Conclusion}

During this study we have observed that $0.5 \%$ bupivacaine reduces immediate post-operative pain significantly as compared to dexamethasone.

However, Dexamethasone reduces postoperative nausea and vomiting significantly as compared to $0.5 \%$ bupivacaine. There were no adverse reactions or complications due to the additional surgical intervention.

\section{What this study adds to the existing knowledge?}

The study statistics confirmed the various parameters like post-operative pain, nausea and vomiting. In view of results of the present study this surgical intervention of local infiltration of $0.5 \%$ bupivacaine in to the tonsillar fossa routinely to minimize the postoperative pain and to encourage early swallowing of solid diet without hampering the healing of tonsillar fossa whereas dexamethasone local infiltration minimizes post-operative nausea and vomiting, thereby reducing the morbidity.

\section{Author's contribution}

Dr.Kommineni Aruna: Surgical intervention incorporation, Data collection, manuscript preparation, review of literature.

Dr. P. S. Sukthankar: Surgical intervention incorporation, results and manuscript correction.

Dr.Preeti S. Raga: Surgical intervention incorporation, Data collection, Review of literature, statistical analysis, manuscript correction.

Acknowledgements: Authors submit their sincere thanks to the department of ENT and management for their cooperation and support

\section{Declarations}

Funding: Nil, Conflict of interest: Nil Permission from IRB: Yes

Ethical approval: The study was approved by the institutional ethics committee 


\section{Original Research Article}

\section{References}

1. Bluestone C.B. Controversies in tonsillectomy and tympanoplasty. Byron. J.Bailey Head and Neck Surgery Otolaryngology New York.Lippincott, Raven publisher, Philadephia, $2^{\text {nd }}$ ed, 1998;1(62):16.

2. Brodsky L. Tonsillitis, tonsillectomy, and adenoidectomy. Head and neck surgery-Otolaryngology. 2001: 979-91.

3. Kaygusuz, Susaman N. The effects of dexamethasone, bupivacaine and topical lidocaine spray on pain after tonsillectomy.Int J Pediatr Otorhinolaryngol. 2003; 67(7):737-742.doi:10.1016/s0165-5876(03)00091-0

4. Lee KC, Bent JP 3rd, Dolitsky JN, Hinchcliffe AM, Mansfield EL, White AK, Surgical advances in tonsillectomy: report of a roundtable discussion. Ear Nose Throat J. 2004;83(8 Suppl 3):4-13.

5. Mallanagoudar H, A comparative study of effects of preoperative intravenous dexamethasone and local infiltration of bupivacaine on post tonsillectomy morbidity, 2010.

6. Gao W, Zhang QR, Jiang L, Geng JY. Comparison of local and intravenous dexamethasone for postoperative pain and recovery after tonsillectomy. Otolaryngol Head Neck Surg. 2015;152(3):530-535. doi: 10.1177/ 0194599814567856. Epub 2015 Jan 20.
7. Younis RT, Lazar RH. History and current practice of tonsillectomy. Laryngoscope. 2002;112(8 Pt 2 Suppl 100): 3-5. doi:10.1002/lary.5541121403

8. Dhingra PL, Acute and Chronic Tonsillitis. In: Dhingra PL. Diseases of Ear, Nose and Throat. 4th ed. Elsevier; 2007; p. 239-240.

9.Wong AK, Bissonnette B, Braude BM, Macdonald RM, St-Louis PJ, Fear DW. Post-tonsillectomy infiltration with bupivacaine reduces immediate postoperative pain in children. Can J Anaesth. 1995; 42 (9): 770-774. doi:10.1007/BF03011174

10. Bhadoria P, Rathore PK, Mandal S, Sehgal R, MeherR, Singh R. Role of Bupivacaine in reducing post tonsillectomy pain. Indian J Otolaryngol Head Neck Surg. 2006;58(4):335-336. doi: 10.1007/BF 03049582.

11. Fradis M, Goldsher M, David JB, Podoshin L. Lifethreatening deep cervical abscess after infiltration of the tonsillar bed for tonsillectomy. Ear Nose Throat J. 1998; 77(5):418-421.

12.Thimmasettaiah NB, Chandrappa RG. A prospective study to compare the effects of pre, intra and postoperative steroid (dexamethasone sodium phosphate) on post tonsillectomy morbidity. J Pharmacol Pharmacother. 2012;3(3):254-258. doi: 10. 4103/ 0976-500X. 99428

\section{How to cite this article?}

Aruna K, Sukthankar P.S, Raga P.S. Comparative analysis of local infiltration of tonsillar fossa with bupivacaine versus dexamethasone on post tonsillectomy morbidity. Trop J Ophthalmol Otolaryngol.2019;4(5):314319.doi:10.17511/jooo.2019.i05.02 